\title{
AS GEOTECNOLOGIAS NA IDENTIFICAÇÃO DE FATORES INFLUENCIADORES DA VULNERABILIDADE DA DISSEMINAÇÃO DA COVID-19: UM ESTUDO DE CASO NA FASE DE REABERTURA DO MUNICÍPIO DE NITERÓI
}

\section{Geotechnologies in the identification of factors influencing the vulnerability of the dissemination of covid-19: a case study in the reopening phase of the Niterói city}

Vitor Hugo Chagas do Vale Pós-Graduando em Geoprocessamento - PUC-MG vitorhvale@gmail.com

Thiago dos Santos Leal Doutorando do Programa de Pós-Graduação em Geografia da UFRJ thiagolealgeo@gmail.com

Luize de Oliveira Ferraro Mello Pós-Graduanda em Dinâmicas Urbano Ambientais e Gestão do Território UERJ luizeferraromello@gmail.com

Ricardo Marinho Soares Braz Graduado em Engenharia de Recursos Hídricos e Meio Ambiente UFF ricardomsbraz@gmail.com

Artigo enviado para publicação em 31/10/2020 e aceito em 01/12/2020

DOI: $10.12957 /$ tamoios.2020.55746

\section{Resumo}

Este artigo tem como objetivo demonstrar os resultados obtidos com a aplicação de ferramentas geotecnológicas para a realização de algumas análises espaciais relacionadas à disseminação dos casos covid-19 na cidade de Niterói (RJ) tendo em vista a flexibilização das medidas de isolamento social praticadas neste município. $O$ desenvolvimento desta pesquisa foi estruturado com base em pesquisa documental do site da Prefeitura de Niterói, levantamento de dados espaciais abertos como número de covid19 casos por bairro entre 15/06/2020 a 27/07/2020, localização de espaços públicos e espaços privados com grande potencial para aglomeração e também localização de aglomerados subnormais. Por fim, foi realizada uma análise da interface entre as variáveis analisadas e a proliferação de covid-19 no período de tempo definido para esta pesquisa. Como resultado, após reabertura entre 22/06/2020 até 29/06/2020, constatou-se que o número de casos aumentou em $39 \%$ em relação ao período anterior. Foram registrados 394 casos novos no bairro de Icaraí, local com maior número de contaminações no município de Niterói. Esses casos se concentraram em áreas com grande densidade de locais religiosos, praças públicas, hospitais, parques urbanos e também áreas próximas as comunidades. Portanto, é possível concluir que a reabertura pode ter impactado no aumento da vulnerabilidade à infecção.

Palavras-chave: covid-19; geotecnologias; administração pública; mapeamento. 


\begin{abstract}
This article aims to demonstrate the results obtained from the application of geotechnology tools to make some spatial analysis related to spread of covid-19 cases in Niterói city (RJ) due to the levels of flexibility of the social isolation measures practiced by the municipality. The development of this research was structured based on documentary research from the Niterói City Hall website, survey of open spatial data such as number of covid-19 cases per neighborhood between 06/15/2020 to 07/27/2020, location of public spaces and private spaces with great potential for agglomeration and location of slums as well. Finally, an analysis of the interface between the variables considered and the covid-19 proliferation over the period of time defined for this research was performed. As a previous result, after reopening between 06/22/2020 to 06/29/2020, it was noted that the number of cases increased by $39 \%$ compared to the previous period. 394 new cases were registered in the neighborhood of Icaraí, the site with the highest number of contaminations in the municipality of Niterói. These cases were concentrated in areas with a high density of religious sites, public squares, hospitals, urban parks and also areas close to slums. Therefore, it's possible to conclude that the reopening may have impacted on the increase of the infection vulnerability.
\end{abstract}

Keywords: Covid-19, geotechnologies, public administration, mapping. 


\section{Introdução}

A disseminação da covid-19 no mundo está gerando inúmeros impactos sociais, políticos, econômicos, expondo a desestruturação de sistemas de saúde e aumentando as morbidades e a mortalidade. Segundo a Financial Times (2020) a América Latina é o atual epicentro das mortes causadas por covid-19 no mundo, sendo esta região a abrigar quase metade do número diário de mortes registrado. Tal dado é principalmente corroborado pelo Brasil, tendo em vista que o país ultrapassou a média diária de 784 mortes, e acumula atualmente 126.650 mil vítimas fatais (Ministério da Saúde, 2020).

Na Região Metropolitana do Rio de Janeiro, o município de Niterói tem se destacado com suas ações contra a disseminação da covid-19, com distribuição de máscaras, cestas básicas, a implantação de renda básica temporária às famílias com renda per capita de meio salário mínimo ou renda familiar de até três salários mínimos mensais, estabelecimento de níveis de restrição à circulação, isolamento social, inclusive decretando lockdown.

Com base na análise dos indicadores estabelecidos pela prefeitura para a aferição do impacto da covid-19 na população e, principalmente a redução do número de internações, a gestão do município, decidiu por uma fase de reabertura. Esta fase apresenta grandes desafios desde a seleção de quais estabelecimentos devem ser liberados até o período de tempo de suas respectivas aberturas. Templos religiosos, hospitais, shoppings, parques urbanos são locais que promovem grande aglomeração.

O monitoramento intenso a partir da análise de vários fatores é de grande relevância pois uma medida equivocada pode gerar retrocessos das ações positivas realizadas anteriormente.

Neste contexto se destaca a variação geográfica, uma vez que estratégias territorializadas tendem a apresentar maior efetividade nas ações de controle, indicando fatores que influenciam na vulnerabilidade. A vulnerabilidade de uma determinada área é estruturada a partir do número de casos e o potencial para evolução da gravidade da doença.

Para além da variação geográfica, o tempo também é um fator central na análise da dinâmica em uma pandemia viral, uma vez que indica a velocidade de disseminação. Enquanto que para análises de fenômenos geológicos os estudos podem ser datados de milhões de anos, em uma pandemia viral a periodização na ordem de dias ou semanas se mostra adequada tendo em vista a rapidez da proliferação da doença e a consequente sobrecarga dos sistemas de saúde, podendo instaurar um quadro caótico (LEAL, et al. 2020).

Nesta continuidade este trabalho objetiva a partir do uso de geotecnologias avaliar a disseminação espaço-temporal da covid-19 na fase de reabertura em diferentes bairros do município com indicações de fatores (locais religiosos, praças, parques urbanos, hospitais, médicos de família, rede de saúde) que podem influenciar na vulnerabilidade da disseminação da doença dada a potencialidade de aglomeração de pessoas, e consequentemente contribuir para a possível formação de uma segunda onda de contágio.

\section{Área de estudo}

A área de estudo está inserida na Região Metropolitana do Rio de Janeiro, e conta com uma população estimada em 2020, segundo dados do IBGE (2020), de 515.317 pessoas. O município de Niterói é limítrofe ao norte com o município de São Gonçalo, à 
oeste do município do Rio de Janeiro e a leste com o município de Maricá (Figura 1), áreas com grande quantitativo populacional e com grande interdependência entre as cidades, sendo a migração pendular uma característica de destaque.

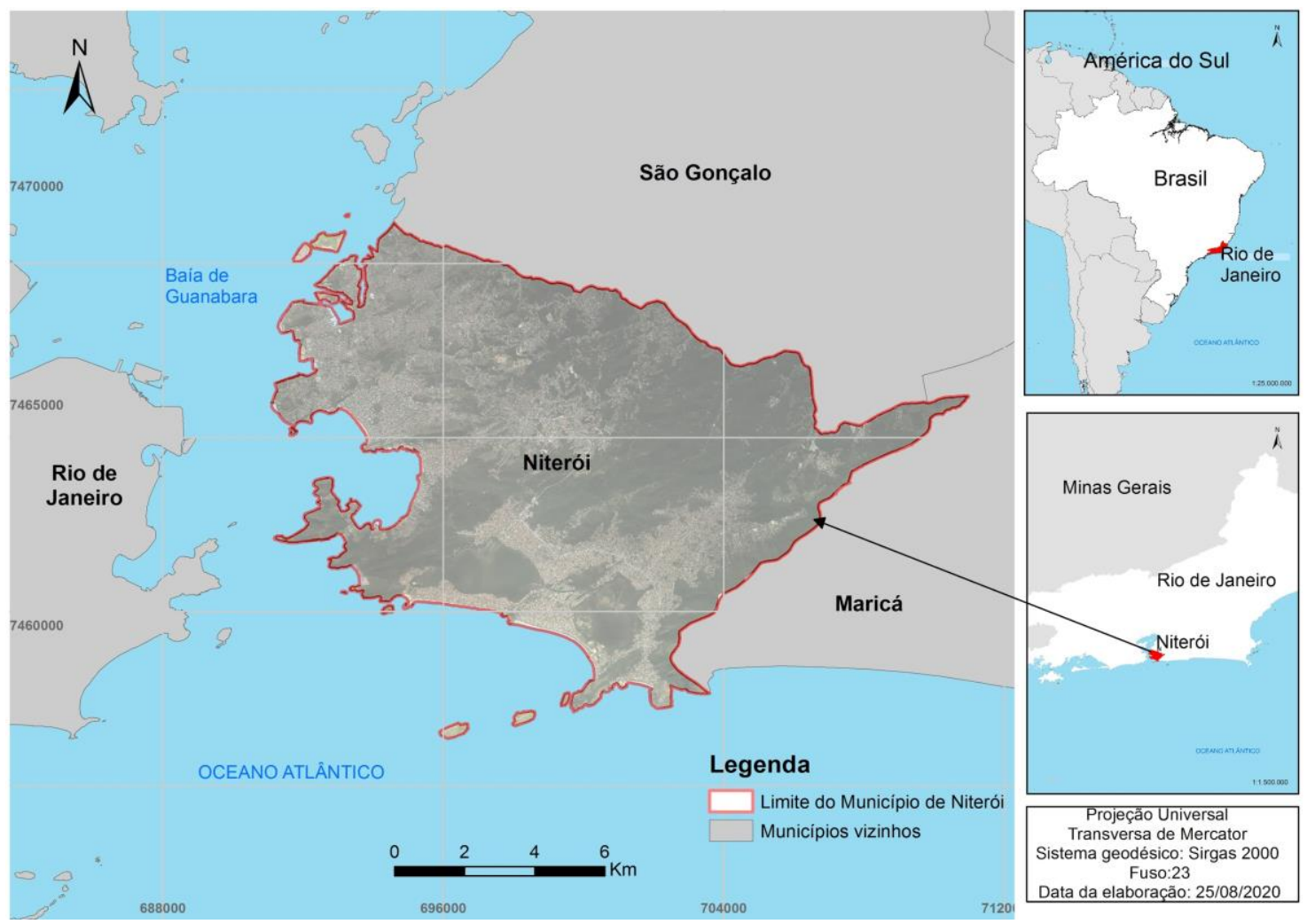

Figura 1 - Localização da área de estudo

Fonte: Elaborado pelos autores.

\section{Materiais e métodos}

O desenvolvimento dessa pesquisa foi estruturado da seguinte forma: 1) pesquisa documental a partir do site da Prefeitura de Niterói (2020) intitulado "Serviços ao Cidadão - Niterói contra o coronavírus" criado especificamente para publicidade as informações sobre covid-19 do município com amplo acervo de atos normativos e ações tomadas até o presente momento e notícias de jornais; 2) Levantamento dos dados espaciais analisados (número de casos de covid-19 por bairro, número de casos de covid-19 entre os dias 15/06/2020 até 27/07/2020, localização de espaços públicos e privados com grande potencial de aglomeração liberados e aglomerados subnormais); 3) Análise da interface das variáveis analisadas e a proliferação da covid-19.

Os dados espaciais dos espaços públicos e privados com grande potencial de aglomeração (locais religiosos, praças, hospitais, médicos de família -PMF-, rede de saúde - postos e policlínicas regionais - e parques urbanos) foram baixados do site do Sistema de Gestão da Geoinformação - SIGeo - da Prefeitura de Niterói (2020).

Foram levantadas também as zonas de espacial interesse social - ZEIS (aglomerados subnormais) uma vez que neste estágio de desenvolvimento da doença a tendência é haver avanço para as áreas periféricas, onde a aglomeração de casas e também de pessoas tende a ser alto, aumentando a possibilidade de contágio.

Para a análise temporal de evolução do número de casos foi selecionada a data de referência 22/06/2020 uma vez que foi a data onde se iniciou a reabertura de parques e 
locais religiosos, conforme indica tabela 1. As análises temporais compreenderam o período de 7 dias, tendo em vista as oscilações de notificação entre os dias de semana e os fins de semana. Assim foram analisados 6 períodos apresentados na tabela 2.

Tabela 1 - Eventos de flexibilização analisados

\begin{tabular}{c|c|c}
\hline Data & Evento & Fonte \\
\hline \multirow{2}{*}{$22 / 06$} & $\begin{array}{c}\text { Flexibilização do comércio de rua, alguns } \\
\text { centros comerciais, abertura de alguns } \\
\text { parques, de clubes e locais religiosos. }\end{array}$ & $\begin{array}{c}\text { PREFEITURA } \\
\text { DE NITERÓI } \\
\end{array}$ \\
\hline
\end{tabular}

Fonte: Elaborado pelos autores

Tabela 2 - Períodos analisados

\begin{tabular}{c|c}
\hline Período & Intervalo temporal \\
\hline 1 & $15 / 06 / 2020$ até $22 / 06 / 2020$ \\
\hline 2 & $22 / 06 / 2020$ até $29 / 06 / 2020$ \\
\hline 3 & $29 / 06 / 2020$ até $06 / 07 / 2020$ \\
\hline 4 & $06 / 07 / 2020$ até $13 / 07 / 2020$ \\
\hline 5 & $13 / 07 / 2020$ até $20 / 07 / 2020$ \\
\hline 6 & $20 / 07 / 2020$ até $27 / 07 / 2020$ \\
\hline
\end{tabular}

Fonte: Elaborado pelos autores

Para o geoprocessamento dos dados foi utilizado o software Arcgis 10.5. Com a finalidade de classificação do resultado foi utilizado o método padrão quebras naturais (jenks natural breaks) para cada período avaliado.

Foi analisada a semana entre o dia 15/06/2020 até 22/06/2020 pois esta semana antecedeu a reabertura. Para identificação da quantidade de casos por bairro em diferentes períodos foram utilizados os boletins diários disponibilizados pela Prefeitura de Niterói em suas redes sociais (Figura 2). Sendo feita a subtração dos casos por período analisado do dia final em relação ao dia inicial. Os bairros analisados no município estão indicados na figura 3 . 


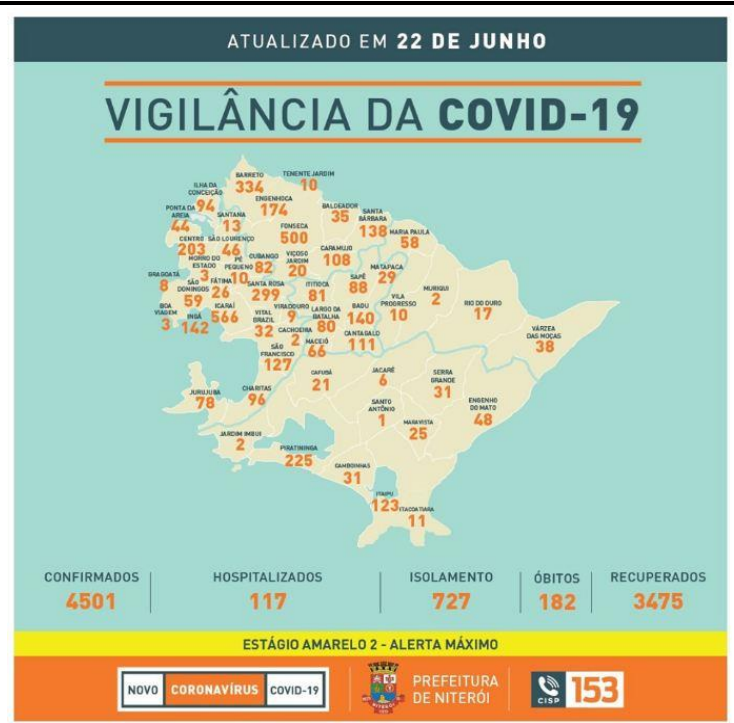

Figura 2 - Boletim diário de casos de covid-19 de Niterói

Fonte: Prefeitura Municipal de Niterói (2020)

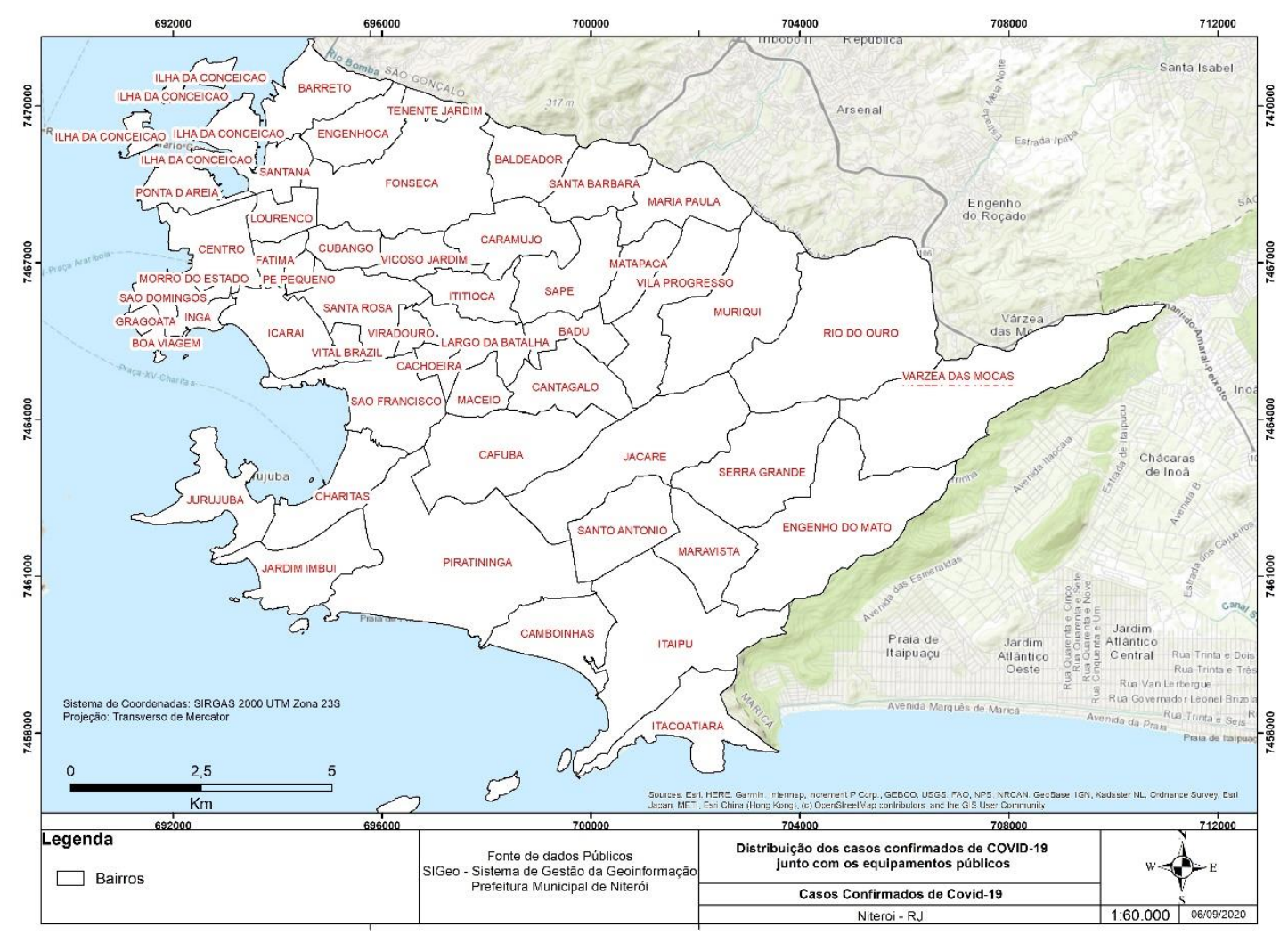

Figura 3 - Indicação dos bairros de Niterói

Fonte: Elaborado pelos autores

\section{Resultados e discussões}

A partir dos dados informados pela Prefeitura Municipal de Niterói e com a finalidade de validar a metodologia proposta, foram elaborados mapas que permitiram a análise espacial do número de casos e dos locais com grande potencial de aglomeração. Na figura 4 é indicada a disseminação da covid-19 uma semana antes da fase de reabertura. 


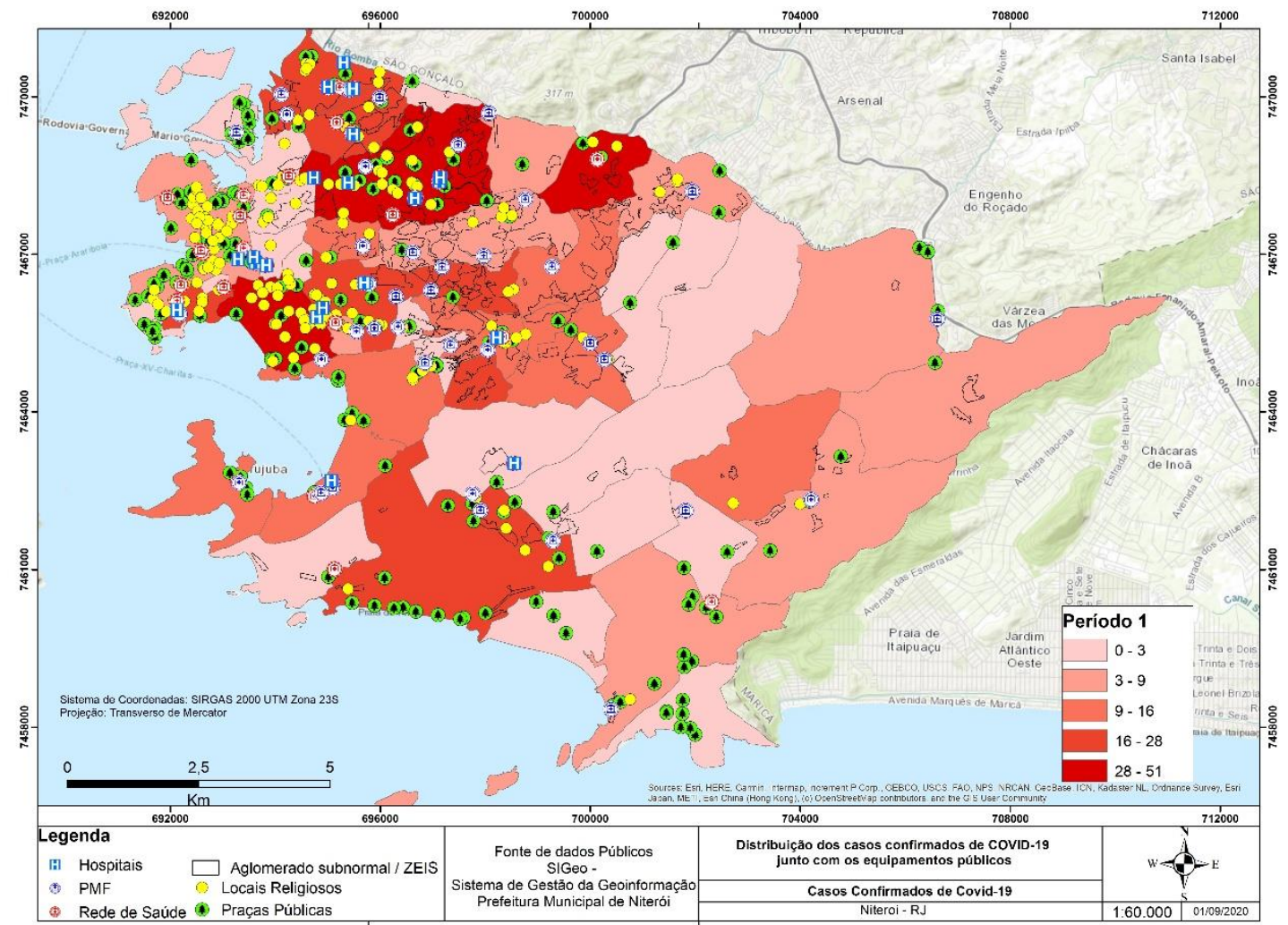

Figura 4: Número de casos e fatores analisados no Período 1 (15/06/2020 até 22/06/2020) Fonte: Elaborado pelos autores

Nota-se neste primeiro período a concentração de casos nos bairros do Fonseca, Icaraí, Piratininga e Baldeador com número de casos no intervalo entre 28 e 51 . Destacase que Icaraí e Fonseca já apresentavam um número relativamente alto de casos desde o início da pandemia, conforme indica o estudo de Leal et al. (2020) sobre a fase inicial da pandemia de covid-19 em Niterói. Esses bairros apresentam um grande adensamento populacional, o que pode ajudar na explicação sobre o número de casos, neste primeiro período de vigência de medidas de isolamento mais restritivas.

Já no segundo período (figura 5), após a reabertura no dia 22/06, o número de casos aumentou de 483 casos da semana anterior para 676, um aumento de $39 \%$ no número de casos, conforme indica a figura 6. Os bairros de Barreto, Fonseca e Icaraí apresentaram um aumento significvativo no número de casos, o que fez com que o método padrão quebras naturais originasse uma nova classe com intervalo entre 38 e 113 casos. Nota-se na figura 5 uma concentração de locais religiosos, praças públicas e infraestrutura de saúde (PMF, hospitais e rede de saúde) nesses bairros, que ao serem liberados para funcionamento influenciaram no aumento de casos.

O estudo de Santos (2008) traz uma importante contribuição a partir dos conceitos de "fixos" e "fluxos" para compreensão das transformações espaciais destacando os circuitos econômicos. Segundo o autor os fluxos são um resultado direto ou indireto das ações e atravessam ou se instalam nos fixos, modificando a sua significação e o seu valor. Já os fixos, enquanto objetos materiais que sofreram mudança e que desempenham função, são econômicos, sociais, culturais, religiosos, etc. Eles são, entre outros, pontos de serviço, pontos produtivos, casas de negócios, hospitais, casas de saúde, ambulatórios, escolas, estádios, piscinas, e outros lugares de lazer.

Alguns destes fixos, portanto, tendem a ser um espaço de concentração de pessoas 
e neste sentido de grande probabilidade de proliferação da covid-19.

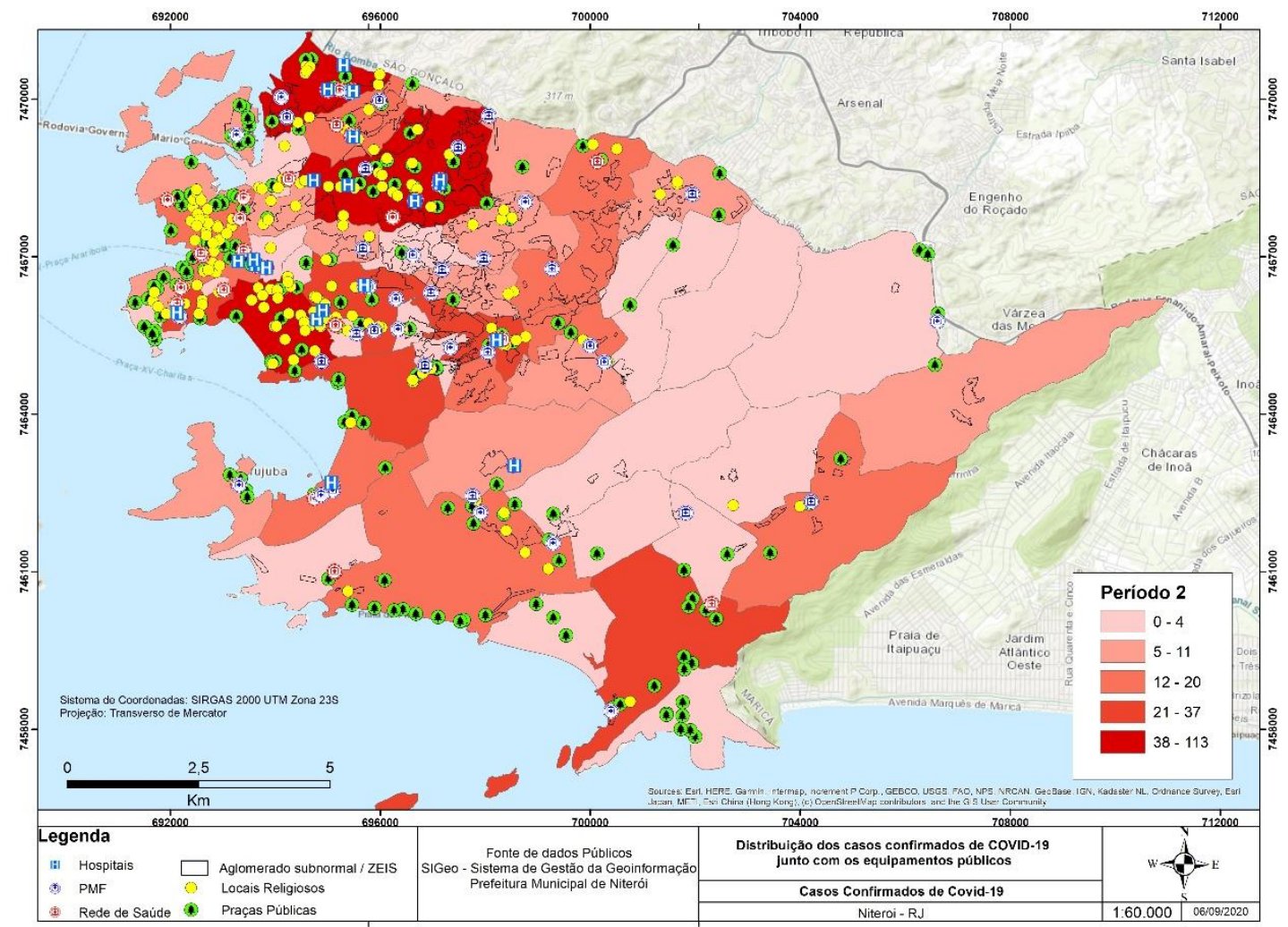

Figura 5: Número de casos e fatores analisados no Período 2 (22/06/2020 até 29/06/2020) Fonte: Elaborado pelos autores

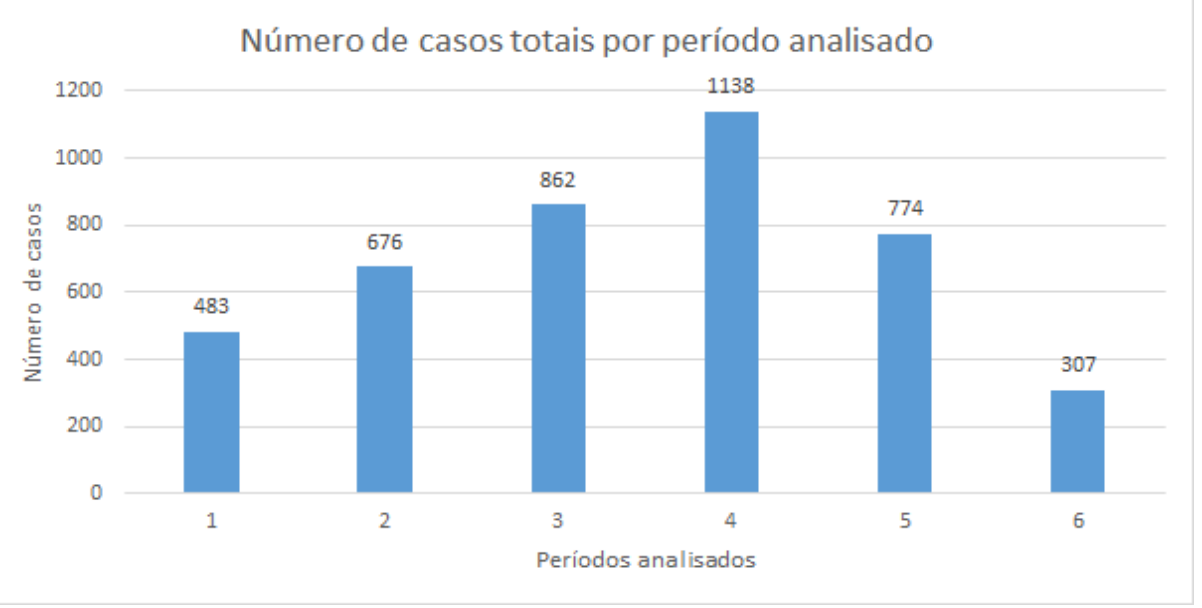

Figura 6: Número casos totais por período analisado Fonte: Elaborado pelos autores

No terceiro (figura 7) e quarto (figura 8) períodos foram notificados 2000 novos casos em Niterói (figura 6), um aumento em relação ao somatório dos períodos 1 e 2 de $72 \%$ no número de casos, correspondendo aproximadamente a $1 / 4$ do total registrado no município em apenas 14 dias. Esses casos se concentraram nas áreas com grande densidade de locais religiosos, praças públicas, rede de saúde, hospitais, parques urbanos e também áreas próximas onde há comunidades. 


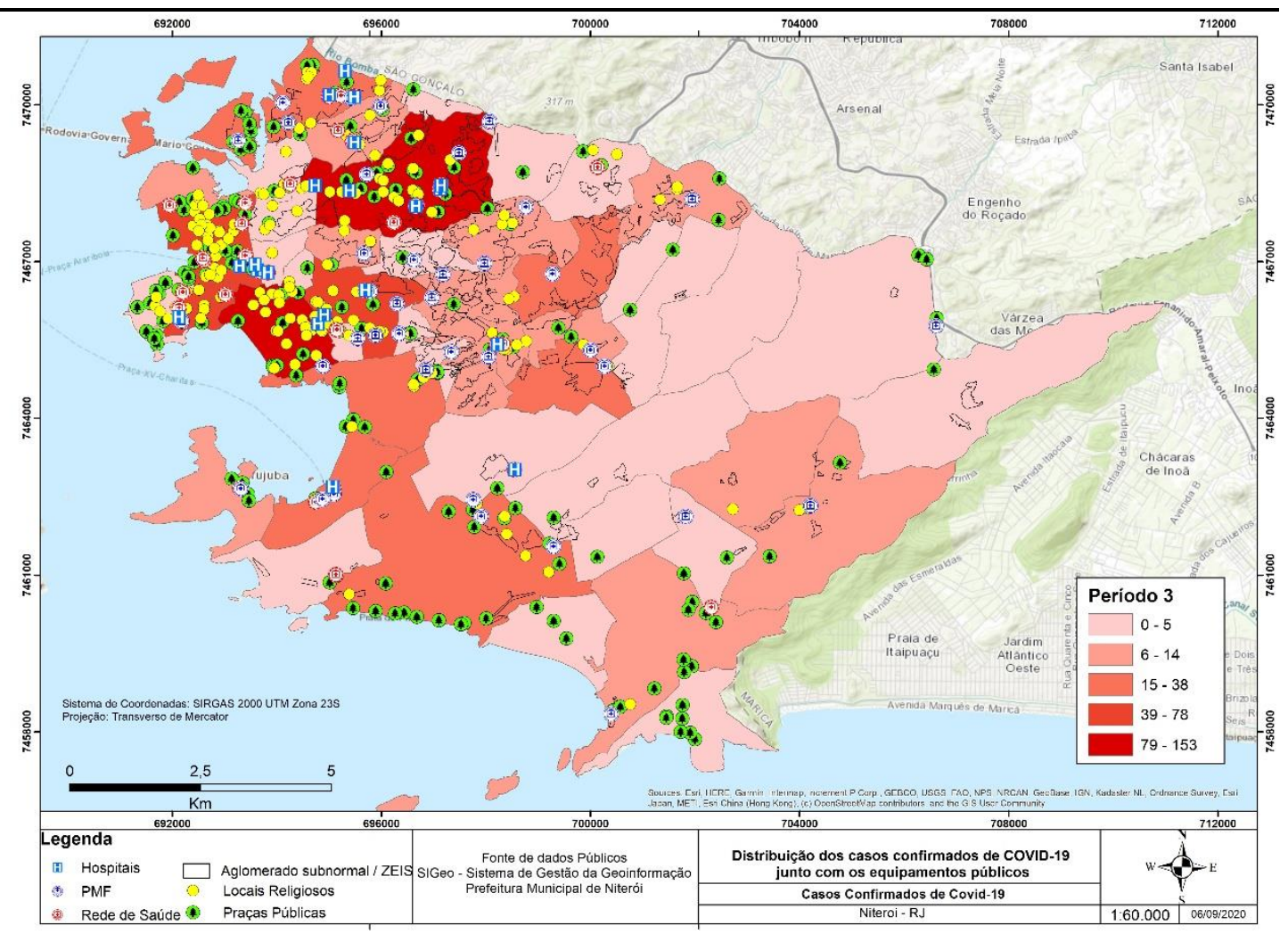

Figura 7: Número de casos e fatores analisados no Período 3 (29/06/2020 até 06/07/2020) Fonte: Elaborado pelos autores

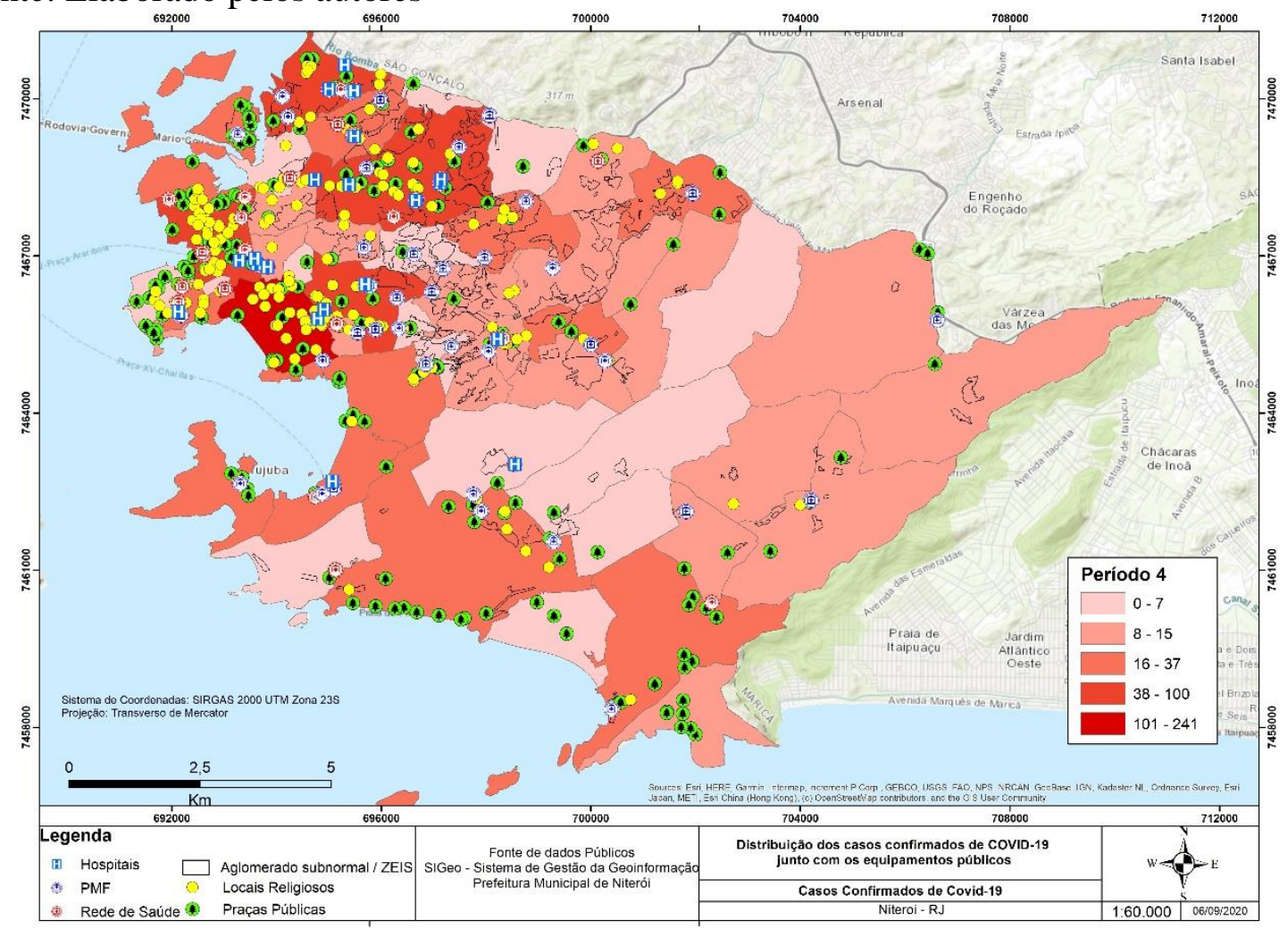

Figura 8: Número de casos e fatores analisados no Período 4 (06/07/2020 até 13/07/2020) Fonte: Elaborado pelos autores

No quinto (figura 9) e sexto (figura 10) períodos ocorre uma queda no número de 
casos de covid-19 de forma inesperada. Uma vez que não houve alteração nas medidas de restrição neste período em relação aos períodos anteriores e nem o descobrimento de cura para doença.

Uma das possíveis causas para a queda está relacionada ao erro na divulgação do boletim diário, o qual apresenta o número de casos no acumulado. Desta forma no dia 20/07/2020 o bairro Maravista apresentava 38 casos, no entanto no dia 27/07/2020 o boletim apresentou "4-"o que fez com que a diferença se tornasse negativa “-34". Em Várzea das Moças ocorreu algo similar, no dia 20/07/20 apresentava 68 casos e no dia 27/07/2020 foram registrados 66 casos, apresentando uma diferença negativa de “-2". Outra possível causa pode estar a uma provável mudança de metodologia de cálculo, algo que já foi apresentado em outros municípios em meio a pandemia.

Os bairros que mais contribuíram para o acréscimo no quinto período analisado foram os bairros de Icaraí, Fonseca, Itaipu, Ingá, Barreto, Engenhoca e Centro, apresentando somados 485 novos casos, o que corresponde a $62,66 \%$ do total de casos registrados no período. Foram registrados 186 novos casos no bairro de Icaraí, local com maior número de contaminações do município de Niterói, correspondendo a 24,03\% do total de casos do quinto período.

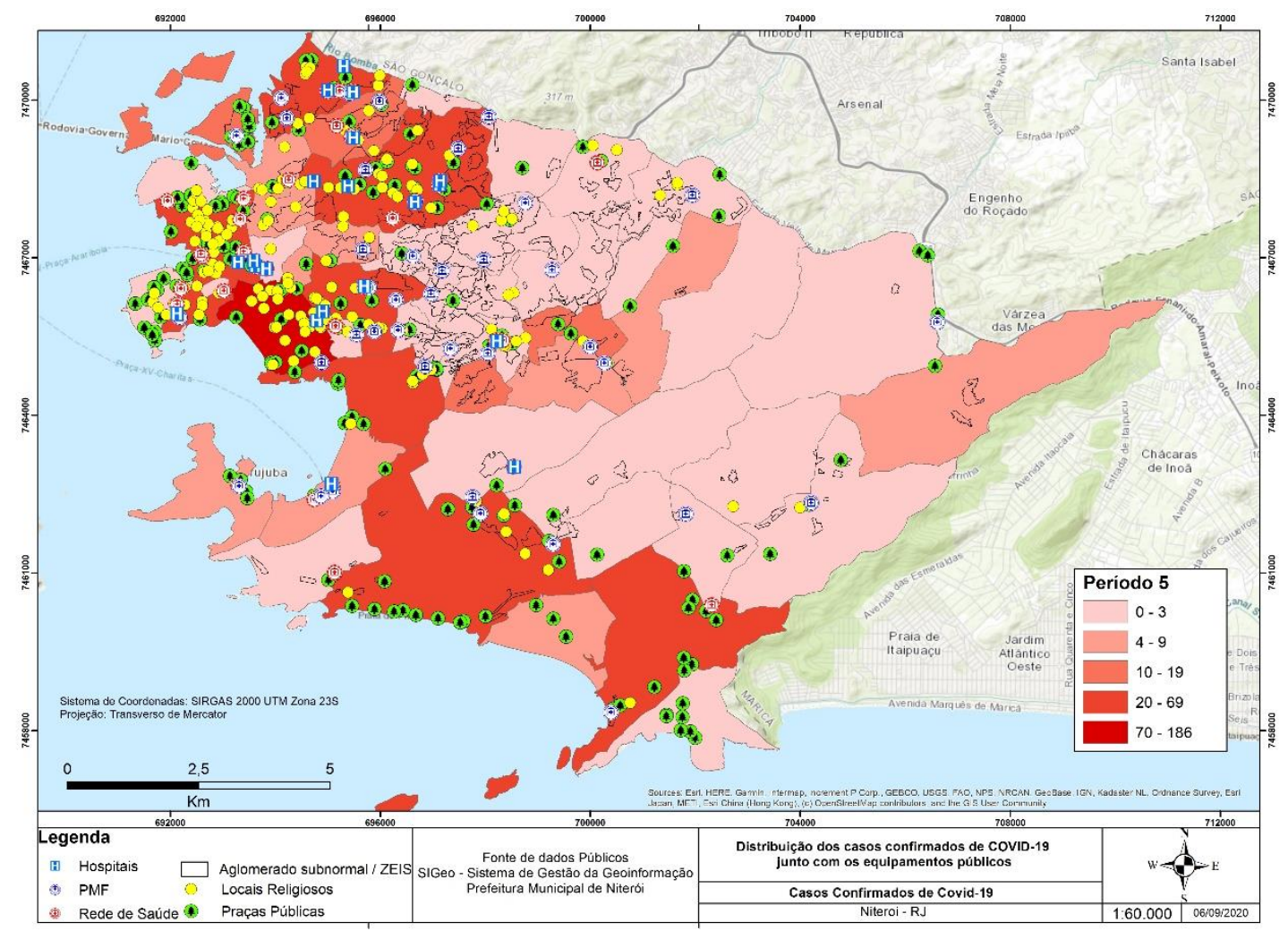

Figura 9: Número de casos e fatores analisados no Período 5 (13/07/2020 até 20/07/2020) Fonte: Elaborado pelos autores

No sexto período (figura 10) os bairros que apresentaram maior número de casos foram Icaraí, Fonseca, Itaipu, Ingá, Barreto, Engenhoca, Centro, Piratininga e Santa Rosa. Estes bairros apresentaram somados 231 novos casos, o que corresponde $75,24 \%$ do total de casos do sexto período. Icaraí no sexto período continua como bairro de maior incidência no número de casos apresentando 57 casos, o que corresponde à $18,56 \%$ do total de casos do período. 


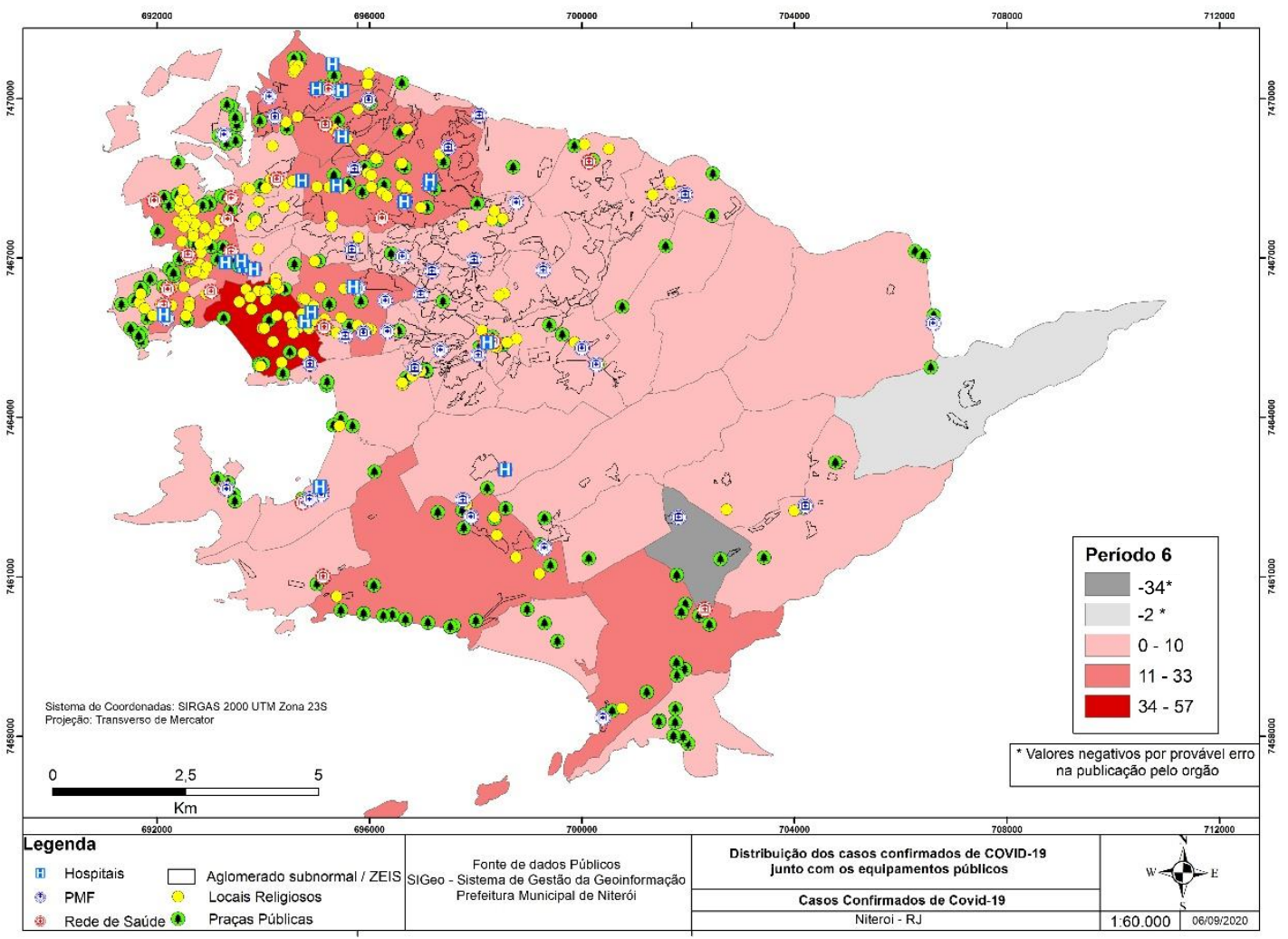

Figura 10: Número de casos e fatores analisados no Período 6 (20/07/2020 até 27/07/2020)

Fonte: Elaborado pelos autores

\section{Considerações finais}

A análise destes dados permitiu identificar a variação dos valores registrados de novas notificações durante a reabertura gradual das atividades. Com a reabertura a contaminação por covid-19 se intensificou nos bairros de maior densidade populacional e que apresentaram maior concentração de equipamentos analisados (as praças, parques urbanos, locais religiosos e unidades de saúde).

Alguns dos bairros apresentados, possuem uma população com renda média baixa, apresentando várias comunidades. O aumento dos casos nessas áreas ocorre a partir da reabertura do comércio e dos demais serviços, os quais representam o setor de maior empregabilidade dessas mesmas parcelas da população, as quais necessitam se deslocar passando a necessitar de utilização dos transportes públicos.

Soma-se a isso os empregos que envolvem atendimento ao direto ao público, tornando o vírus que se iniciou na classe alta e média alta, em um vírus difuso em termos de contágio, no entanto com consequências desiguais entre as classes sociais.

Ao se concluir é percebido que a reabertura econômica em uma pandemia, é algo muito sensível, que abrange várias necessidades e realidades. $\mathrm{O}$ fato é que o controle e fiscalização precisam acontecer e as normas cumpridas, não se tratando do individual, mas do coletivo e de vidas. 


\section{Referências bibliográficas:}

BRASIL. Ministério da Saúde. Painel Coronavírus. Atualizado em: 06/09/2020 às 19:00. Disponível em <https://covid.saude.gov.br/> Acesso em 07/09/2020.

FINANCIAL TIMES (2020). Coronavirus tracked: the latest figures as countries reopen. Disponível em <https://www.ft.com/content/a2901ce8-5eb7-4633-b89c-cbdf5b386938> Acesso em 01/09/2020.

LEAL, T. S.; ROCHA-LEÃO, O. M.; BARROS, R. S.; REZENDE, P. P. B. Dinâmica espaço-temporal na propagação da COVID19 em Niterói (RJ): uma contribuição geográfica na análise da suscetibilidade e da vulnerabilidade socioambiental na fase inicial da pandemia. Rev. Tamoios, São Gonçalo (RJ), ano 16, n. 1, Especial COVID-19. pág. 108-124, maio 2020.

SANTOS, M.. O espaço dividido: Os dois circuitos da economia urbana dos países subdesenvolvidos. São Paulo: Edusp, 2008.

PREFEITURA DE NITERÓI. Serviços ao Cidadão - Niterói contra o coronavírus. Disponível em <https://www.coronavirus.niteroi.rj.gov.br/\#/main/dyview> Acesso em 30/08/2020.

G1 GLOBO, Niterói reabre shoppings e centros comerciais com restrições nesta quarta. Disponível em <https://g1.globo.com/rj/rio-dejaneiro/noticia/2020/07/01/niteroi-reabre-shoppings-e-centros-comerciais-comrestricoes-nesta-quarta.ghtml> Acesso em 07/09/2020 